\title{
Relation Between Side of Plagiocephaly, Dislocation of Hip, Scoliosis, Bat Ears, and Sternomastoid Tumours
}

\author{
GEOFFREY H. WATSON \\ From Royal Manchester Children's Hospital and the University Department of Child Health, St. Mary's Hospitals, \\ Manchester
}

\begin{abstract}
Watson, G. H. (1971). Archives of Disease in Childhood, 46, 203. The relationship between the side of plagiocephaly, dislocation of the hip, scoliosis, bat ears, and sternomastoid tumours. A relation is described between plagiocephaly and four structural lesions in children who have two or more of these five features. The flat temple in plagiocephaly, a unilateral congenitally dislocated hip, a scoliotic convexity in a young child, and a sternomastoid tumour tend to be on the same side, and a unilateral bat ear on the opposite side.
\end{abstract}

Plagiocephaly is a common asymmetry of the skull which looks as if it has been compressed along a horizontal axis between one temple and the opposite side of the occiput. It is often seen in normal people, and is only very rarely due to underlying disease or malformation of the skull; such cases are not discussed here. The observation of plagiocephaly in a few children seen because of congenital dislocation of the hip $(\mathrm{CDH})$ prompted a larger survey, which later extended to include normal children and children with bat ears, scoliosis, and sternomastoid tumours.

\section{Methods and Material}

The degree of plagiocephaly, if present, was estimated by inspection from above using a simple device of rulers (Fig.). The front ruler AC was arranged parallel to the centres of the corneae, while the horizontal parallel rulers DAE (fixed perpendicular to $A B C$ ) and FG (movable on pivoted connecting bars DF and EG) touched the sides of the head at its widest part; the ratio of the greater to the lesser of the distances of $A$ and $\mathrm{B}$ from a mark $\mathrm{X}$ on the middle of the forehead was expressed as a 'plagiocephaly index'. Thus an index of ' $L 1 \cdot 25$ ' indicated a skull with very marked flattening of the left temple and right occipital region. Plagiocephaly in this direction is referred to as 'left-sided'. The reproducibility of results varied with the shape of the skull, but the greatest range of indices when measurements of 20 children were repeated on six different occasions was within +0.04 of the mean of each. To avoid false positives, skulls with an index of less than $1 \cdot 10$ were therefore regarded as symmetrical, and in this paper the word 'plagiocephaly' is applied only to skulls with an index of 1.10 or more. In general only the

Received 10 August 1970. presence or absence of plagiocephaly is discussed, and not the degree, which except where mentioned did not seem to correlate with features of the lesions in question. Correlations were assessed by a $\chi^{2}$ test.

The patients had all attended one or other of the three Manchester Children's Hospitals. Those with major neurological lesions, mental retardation, 'arthrogryposis', multiple congenital anomalies, and lesions likely to cause disturbances of movement in infancy were excluded, though of course a number of children included because of their CDH had a striking laxity of the joints (Carter and Wilkinson, 1964). The normal people were seen at Welfare Clinics.

CDH. Nearly all the 107 children presented with symptoms referrable to the hip, having been born some years ago before effective routine neonatal examination of the hips had become widespread. The ratio of females to males $(6 / 1)$, the preponderance of the left side, and the frequencies of a positive family history $(10 \%)$, breech delivery $(9 \%)$, and prematurity $(5 \%)$ were much the same as in other series. Cases were included only if an $x$-ray clearly showed at least $50 \%$ luxation of one or both hips: infants with only instability of the hips were not included. Cases with one hip dislocated and the other obviously abnormal but displaced less than $50 \%$ were placed in a separate category (left $>$ right, or right $>$ left).

Bat ears. The 17 children had mostly attended with a view to operation; a few had been noticed in infancy to have gross bat ears. The prominence of the ear was usually due to flattening or absence of the antihelical fold; the ears could all be manipulated into a normal configuration and were not otherwise malformed. Children with symmetrical bat ears were not included; those included therefore all had one ear which was either normal (10 cases) or only slightly protruding ( 7 cases). 


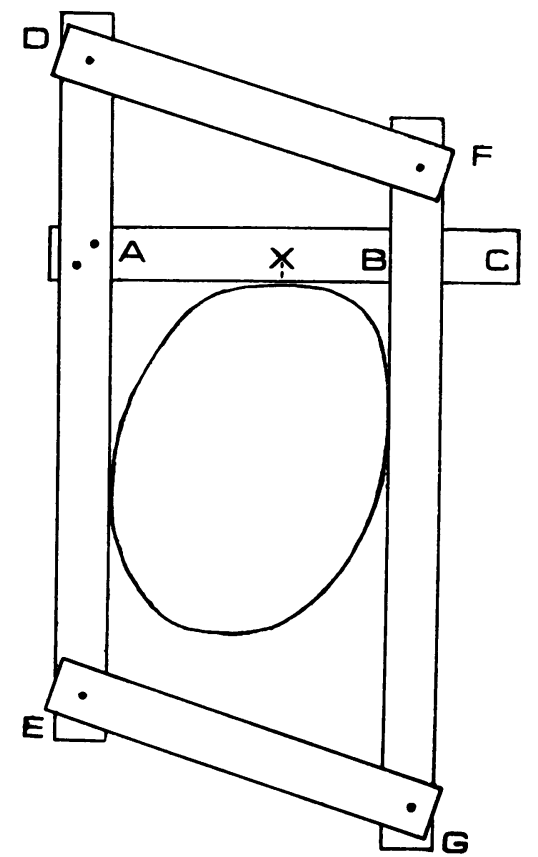

Scoliosis. The $\mathbf{4 8}$ children had all attended because of a spinal curve except for 4 with congenital cardiac lesions, in whom the spinal curve had been noticed in infancy before any significant cardiac symptoms had appeared. 11 had vertebral anomalies; the rest had idiopathic scoliosis with no obvious cause. In each case there was a general curve or a mid or lower dorsal primary curve; a few children were also seen with double curves. Exclusion of the children whose parents had brought them for reasons other than their bat ears or scoliosis did not affect the conclusions.

Sternomastoid tumours. The children with sternomastoid tumours had nearly all attended because of the tumour, and except where noted none had other significant anomalies.

\section{Results}

Normal subjects. Table I shows the distribution of plagiocephaly in apparently normal children and adults, mostly female; this includes the parents of children with $\mathrm{CDH}$, whose pattern of plagiocephaly did not differ from that of other apparently normal adults. Left-sided plagiocephaly is about twice as common as right-sided in both children and adults. Few small infants were included, because reliable measurement was not always possible; often however, plagiocephaly is only slight at birth and increases during the first few weeks of life. Subsequently, as the Table shows,
TABLE I

Normal People

\begin{tabular}{|c|c|c|c|c|}
\hline \multirow{2}{*}{$\begin{array}{l}\text { Age } \\
(\mathrm{yr})\end{array}$} & \multirow{2}{*}{$\begin{array}{l}\text { No. of } \\
\text { Cases }\end{array}$} & \multirow{2}{*}{$\begin{array}{c}\% \text { with } \\
\text { Plagiocephaly }\end{array}$} & \multicolumn{2}{|c|}{$\begin{array}{l}\text { No. with } \\
\text { Plagiocephaly }\end{array}$} \\
\hline & & & Left & Right \\
\hline $\begin{array}{c}<1 \\
1-4 \\
4-10 \\
10-16 \\
\text { Mothers }\end{array}$ & $\begin{array}{r}65 \\
81 \\
40 \\
50 \\
249\end{array}$ & $\begin{array}{l}48 \\
41 \\
32 \\
40 \\
14\end{array}$ & $\begin{array}{l}20 \\
20 \\
11 \\
14 \\
26\end{array}$ & $\begin{array}{r}11 \\
13 \\
2 \\
6 \\
9\end{array}$ \\
\hline Total & 485 & & 91 & 41 \\
\hline
\end{tabular}

plagiocephaly becomes less frequent, in agreement with common observation. Severe plagiocephaly also becomes rarer. There was no correlation between the presence or side of plagiocephaly in mothers and in their children, and no correlation between the side or degree of plagiocephaly and birth order or trauma in any of the groups.

CDH. Table II relates the degree and side of plagiocephaly with the type of $\mathrm{CDH}$. Though most cases of $\mathrm{CDH}$ did not have plagiocephaly, in children with unilateral $\mathrm{CDH}$ who had plagiocephaly it was invariably the ipsilateral temple

TABLE II

\begin{tabular}{|c|c|c|c|c|}
\hline \multirow{2}{*}{$\begin{array}{l}\text { Type } \\
\text { of } \\
\text { CDH }\end{array}$} & \multirow{2}{*}{$\begin{array}{c}\text { No. } \\
\text { of } \\
\text { Cases }\end{array}$} & \multicolumn{2}{|c|}{ Plagiocephaly } & \multirow{2}{*}{$\begin{array}{c}\% \\
\text { with } \\
\text { Plagiocephaly }\end{array}$} \\
\hline & & Left & Right & \\
\hline \multirow[t]{2}{*}{$\begin{array}{l}\text { Left } \\
\text { Right } \\
\text { Left }>\text { Right } \\
\text { Left }=\text { Right } \\
\text { Right }>\text { Left }\end{array}$} & $\begin{array}{r}64 \\
16 \\
7 \\
15 \\
5\end{array}$ & $\begin{array}{l}\frac{29}{1} \\
-\end{array}$ & $\left.\begin{array}{c}\frac{5}{1} \\
1\end{array}\right\}$ & $\begin{array}{l}45 \\
31 \\
22\end{array}$ \\
\hline & 107 & 33 & 7 & 37 \\
\hline
\end{tabular}

that was flattened. The difference from the distribution which would be expected from the normal figures is highly significant $(P<0 \cdot 001)$. The same pattern was seen in the 2 cases of bilateral $\mathrm{CDH}$ where one side was only mildly abnormal: in each, temple flattening was on the side of the worse hip.

Unilateral $\mathrm{CDH}$ is much more commonly leftsided, and the ratio of left- to right-sided plagiocephaly was correspondingly much greater than in normal people.

In addition, about one-third of the children with unilateral $\mathrm{CDH}$ with no plagiocephaly nevertheless had some flattening of one temple, even though 
there was no major skull asymmetry; this flattening was also nearly always on the side of the affected hip.

Table II suggests that plagiocephaly is more frequent in children with unilateral than in those with bilateral $\mathrm{CDH}$. The incidence of plagiocephaly irrespective of side was, however, not significantly different over the whole group of cases of $\mathrm{CDH}$ from that in normal children of similar age (Table III).

TABLE III

Congenital Dislocation of Hip

\begin{tabular}{c|c|c}
\hline Age (yr) & No. of Cases & \% with Plagiocephaly \\
\hline$<1$ & 5 & $60(48)^{\star}$ \\
$1-4$ & 39 & $36(41)$ \\
$4-10$ & 35 & $40(32)$ \\
$10-16$ & 28 & $32(40)$ \\
\hline & 107 & \\
\hline
\end{tabular}

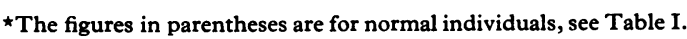

No suggestion of any further correlation was found after considering other factors-sex, the presence of a family history of $\mathrm{CDH}$, premature birth, the presence of general laxity of the joints, the duration of treatment, and the presence of plagiocephaly in mothers and sibs of patientsthough for some of these factors cases were too few for significance.

Bat ears. Table IV shows that the bat ear, or the worse ear if both are affected, is on the side opposite to the flat temple in children who have plagiocephaly, the difference from the distribution expected if there were no association being highly significant $(p<0.001)$. There also appears to be

TABLE IV

Unilateral Bat Ear

\begin{tabular}{l|c|c|c}
\hline \multirow{3}{*}{ Side of Bat Ear } & No. of Cases & \multicolumn{2}{|c|}{ No. with Plagiocephaly } \\
\cline { 2 - 4 } & & Left & Right \\
\hline Left & 7 & 0 & 5 \\
Right & 10 & 8 & 0 \\
\hline
\end{tabular}

an unduly high frequency of plagiocephaly in children with asymmetrical bat ears. Temple flattening in the same sense was also present in most of those without plagiocephaly. A similar pattern can often be seen in normal infants with minor degrees of bat ears, which tend to improve with time and do not come to operation; 12 of the cases reviewed here were over 5 years of age, and all 17 were candidates for operation. Plagiocephaly was as common in the familial cases (in 4 of 6) as in the 11 without family history, and both its frequency and its severity were the same in those whose bat ear was seen soon after birth as in those whose bat ear was first noticed later.

Scoliosis. Table V shows the relation between the side of scoliosis and that of plagiocephaly when present. In idiopathic scoliosis appearing in the first two years of life, plagiocephaly was clearly

\begin{tabular}{|c|c|c|c|c|}
\hline \multirow[t]{2}{*}{ Type } & \multirow{2}{*}{$\begin{array}{l}\text { Side of } \\
\text { Convexity }\end{array}$} & \multirow{2}{*}{$\begin{array}{l}\text { No. of } \\
\text { Cases }\end{array}$} & \multicolumn{2}{|c|}{$\begin{array}{c}\text { No. with } \\
\text { Plagiocephaly* }\end{array}$} \\
\hline & & & Left & Right \\
\hline $\begin{array}{l}\text { Idiopathic, first } \\
\text { seen age } 0-2 \text { yr } \\
\text { Idiopathic, first } \\
\text { seen age } 2-14 \mathrm{yr} \\
\text { With vertebral } \\
\text { anomalies }\end{array}$ & 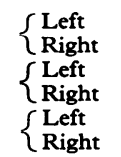 & $\begin{array}{r}15 \\
4 \\
3 \\
15 \\
6 \\
5\end{array}$ & $\begin{array}{r}12(1) \\
0(1) \\
0(2) \\
0(0) \\
2(0) \\
1(1)\end{array}$ & $\begin{array}{l}0(1) \\
3 \\
0(0) \\
1(7) \\
1(1) \\
1(0)\end{array}$ \\
\hline
\end{tabular}

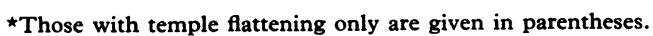

unusually frequent, and on the same side as the convexity; it was also unusually severe. The same pattern was seen in the 'resolving' as in the 'progressive' form of scoliosis. In children whose scoliosis was not noticed until after the age of 2 plagiocephaly was uncommon, but temple flattening, when present in those without plagiocephaly, was again on the side of the spinal convexity. No correlation was found in the few cases of scoliosis due to vertebral anomalies. The striking excess of convexities to the left in infants and to the right in later childhood is well known but unexplained.

In 7 further children with a complex or double curve there was a tendency for the flat temple to be on the side of the convexity of the thoracic curve if present, and the opposite was not encountered, but cases were too few for significance.

Sternomastoid tumours. Table VI relates the presence and side of plagiocephaly to the side of the sternomastoid tumour. There is clearly a close correlation $(p<0.001)$ between the side of the tumour and the direction of plagiocephaly, when present, only one case showing plagiocephaly on the side opposite to that of the tumour. Table VII, column (a), shows that plagiocephaly is little if any 
TABLE VI

Sternomastoid Tumour

\begin{tabular}{|c|c|c|c|}
\hline \multirow{2}{*}{ Side of Tumour } & \multirow{2}{*}{ No. of Cases } & \multicolumn{2}{|c|}{ No. with Plagiocephaly } \\
\hline & & Left & Right \\
\hline \multirow[t]{2}{*}{$\begin{array}{l}\text { Left } \\
\text { Right }\end{array}$} & $\begin{array}{l}18 \\
24\end{array}$ & $\begin{array}{r}10 \\
1\end{array}$ & $-\frac{}{7}$ \\
\hline & 42 & \multicolumn{2}{|c|}{$18=43 \%$} \\
\hline
\end{tabular}

more common than in the control cases of similar age. As in $\mathrm{CDH}$ a number of children with sternomastoid tumours but no plagiocephaly had ipsilateral temple flattening.

TABLE VII

Sternomastoid Tumour

\begin{tabular}{c|r|c|c}
\hline $\begin{array}{c}\text { Age when } \\
\text { Examined } \\
\text { (yr) }\end{array}$ & No. & $\begin{array}{c}\text { (a) } \\
\text { \% with } \\
\text { Plagiocephaly }\end{array}$ & $\begin{array}{c}\text { (b) } \\
\text { No. with Uptilted } \\
\text { Mandible }\end{array}$ \\
\hline$<1$ & 12 & $50(48)^{\star}$ & 10 \\
$1-4$ & 9 & $64(41)$ & 3 \\
$4-10$ & 14 & $43(34)$ & 2 \\
$10+$ & 7 & $14(40)$ & 1 \\
\hline Total & 42 & 43 & 16 \\
\hline Total, aged & 30 & 40 & 6 \\
$>1$ year & & & \\
\hline
\end{tabular}

$\star$ The figures in parentheses are for normal subjects, see Table I.

The data presented above suggest a close relation between the side of plagiocephaly, when present, and the side of the lesions discussed. Plagiocephaly, and unilateral temple flattening if present in patients without plagiocephaly, tend to be on the same side as a unilateral hip dislocation, a sternomastoid tumour, and the convexity of an infantile idiopathic scoliosis, and on the opposite side to a unilateral bat ear. A similar pattern was seen in children with coexisting lesions (each is included only once in the Tables above).

(a) Children seen because of CDH. One child of 14 years with a right-sided $\mathrm{CDH}$ had a left-sided bat ear and a conspicuous right plagiocephaly; another child of $2 \frac{1}{2}$ with a left $\mathrm{CDH}$ had a right bat ear seen at birth, but a symmetrical skull. One child of 14 with equal bilateral $\mathrm{CDH}$ and no plagiocephaly, but some flattening of the right temple, had had a right sternomastoid tumour in infancy; and a child of 3 with a rightsided $\mathrm{CDH}$ and right plagiocephaly had had a right sternomastoid tumour in infancy. (b) Children seen because of bat ear. One boy of 10 years with a left-sided familial bat ear had a middorsal scoliosis convex to the right, and right plagiocephaly. One infant with a conspicuous persistent left bat ear present from birth had a right-sided sternomastoid tumour, and a general resolving scoliosis convex to the right present from birth. He had slight right temple flattening but no significant plagiocephaly. He also had a ventricular septal defect with, however, no symptoms when first seen.

(c) Children seen because of scoliosis. One child of 8 with severe lower dorsal scoliosis convex to the left also had had a left-sided $\mathrm{CDH}$, and marked flattening of the left temple. An infant of 2 months had a resolving left-sided scoliotic convexity, left plagiocephaly, and a marked right-sided bat ear present at birth and persisting.

(d) Children seen because of sternomastoid tumour. One child encountered elsewhere with a left-sided sternomastoid tumour, and not included in the figures, also had a right-sided bat ear, and slight left temple flattening though no plagiocephaly. Another infant with conspicuous left-sided plagiocephaly and a left sternomastoid tumour had a left-sided dislocated hip.

In addition, Dr. R. Wynne-Davies has kindly allowed me to quote 4 cases of scoliosis in the Edinburgh survey (Wynne-Davies, 1968) who also had CDH. Two of them had bilateral $\mathrm{CDH}$, but in two infants with unilateral $\mathrm{CDH}$ and a thoracic scoliosis the spinal convexity was again on the same side as the dislocated hip (one had left-sided and progressive scoliosis, one rightsided and resolving).

\section{Discussion}

Plagiocephaly has been ascribed to intrauterine pressure, or to the position before and during birth: a left occipito-anterior presentation might lead to (but might perhaps be produced by) leftsided plagiocephaly, both of these being of course on the more common side. Review of the obstetric case sheets of some normal infants with plagiocephaly has not suggested any close correlation with the position either during or before birth, though Jones (1968) and Danby (1962) found some correlation. The posture of the infant, irrespective of its position in the uterus, may, however, be significant. The uterus is not in general round in transverse section, except during contractions, but commonly flattened from front to back. Even if the fetus as a whole can change its position, perhaps when the uterus at times becomes rounder in crosssection through contraction, or if the mother lies on her side, it might still be restricted in the same way if the fetus rotated, for example, about an anteroposterior maternal axis, or through $180^{\circ}$ 
about a vertical maternal axis. In this way there may be some restriction of fetal movement for much of the day in later pregnancy, and the fetus might tend to resign itself to a 'position of comfort' (Chapple, 1959) and might continue to grow, if it has once started to do so, into a more oblique shape, without actual compression or oligohydramnios. This might account for the observation, in some infants with marked plagiocephaly, of a similar deformity of the chest in the same sense. In some such infants there may also be a temporary neonatal limitation of hip abduction on the same side as the anterolateral flattening of the chest and skull. Conceivably such a hip might be the one to dislocate if other predisposing factors were present; on the other hand, if non-postural factors had caused a unilateral prenatal dislocation, then the resulting asymmetry might determine the side of plagiocephaly, if present. Similar remarks apply to scoliosis.

Plagiocephaly is well known in children who spend their lives in bed through brain damage, and it seems very likely that the skull changes in such children are the result of limited movement and constant pressure in one direction. None of the children discussed in this paper had been restricted in movement since birth, either by disease or policy, except of course those treated by long rest supine in bed for CDH. The pattern of plagiocephaly was, however, seen in those who had not been so treated, and did not seem to be any more marked in those with CDH who in the past had had long treatment than in those who, when seen, had been treated for only a short time or not at all.

Some infants with marked plagiocephaly insist on lying on the flat side of the occiput, and this may of course tend to delay the usual lessening of the asymmetry. One can only speculate that this is related to the tendency of infants to prefer a position of comfort, similar to their intrauterine posture, as if they were used to that part of the occiput, rather than the other side, being in contact with the uterine wall. In the present series inquiries on these lines were unfruitful.

Plagiocephaly often seems to get worse, and may even seem to develop first, during the first few weeks of life. Conceivably moulding during birth, which would tend to make the head rounder in a plane perpendicular to the path of delivery, could temporarily diminish a prenatal plagiocephaly, though the plagiocephaly sometimes seems to progress for longer than moulding takes to disappear. However, in general at least some mild frontal asymmetry can be seen soon after birth in infants who later show more marked plagiocephaly, and it seems likely therefore that the side of the asymmetry is prenatally determined.

I have found no published reference to plagiocephaly in CDH. This may well be because the presenting lesion is not near the skull and has usually been regarded as a local matter, and also because plagiocephaly is present in only a minority of cases, is not always obvious, and is often not noticed at all, perhaps because we have grown used to it as a common and normal feature. Very few of the children with $\mathrm{CDH}$ were seen soon after birth, and it is possible that both the dislocation and plagiocephaly might have been acquired after birth. Four patients, however, were seen soon after birth in whom a unilateral CDH was clearly present then, and was associated with a meningomyelocele. Of these one had a symmetrical skull; the other three had left-sided CDH and conspicuous flattening of the left temple, thus showing the same pattern as in the main series.

None of the patients reviewed here was a negro, and personal observation suggests that plagiocephaly is rare in negroes, though it occurs in halfcaste children. Possibly this fact may be linked in some way with the rarity of $\mathrm{CDH}$ in negroes (Ferguson, 1963).

I have also failed to find any direct reference to the relation of bat ears and plagiocephaly except in connexion with torticollis, though no doubt it has been noticed before. Infants are sometimes noticed at birth to have one ear folded forwards, and such ears often remain more protuberant than the other, though they may become symmetrical later. Such infants often have plagiocephaly, and if they are folded into the probable intrauterine posture it often becomes apparent that the folded ear has been on a convex outer part of the fetal mass, against the uterine wall, while the other ear has not. It is easy to see how such ears may be held in a folded position after birth in those infants who insist on lying upon that side, and not unreasonable to suggest that a similar mechanism may have applied in utero, though other factors are presumably also in operation. A similar mechanism may well explain an appearance seen in four other children, who had one normal and one abnormal ear, which was of normal height but narrow though not protruding. It looked as if it had been compressed by a force acting on its edge, but not completely folding it forwards. In each case there was plagiocephaly on the opposite side, just as in the cases of unilateral bat ears.

The association of plagiocephaly with congenital idiopathic scoliosis has been known for many years. It is mentioned in orthopaedic textbooks and is 
noted again by Wynne-Davies (1968). This author, in a large series, found plagiocephaly on the side of the spinal convexity in all scoliotic infants under 1 year old, but not in older patients. She found plagiocephaly in only $11 \%$ of normal infants, equally on the two sides; presumably the criteria used were stricter than those in the present series. She also points out (personal communication) that plagiocephaly was not associated with the side of the convexity in children with scoliosis due to vertebral anomalies. On the other hand Jones (1968) quotes 14 infants with idiopathic scoliosis of whom 5 had plagiocephaly on the opposite side to the convexity. He says, however, that in general his cases had only slight scoliosis, whereas all cases in the present series had clinically very obvious scoliosis.

Plagiocephaly in this series was closely but not invariably associated with the side of the sternomastoid tumour. Of 7 patients in this series seen in the first few weeks of life, 3 had symmetrical skulls, 3 had a tumour on the same side as the flat temple, and 1 had a tumour on the opposite side. Jones (1968) found 5 'discordant' cases in 16 infants with sternomastoid tumours seen soon after birth. However, in plagiocephalic infants in both series there were no 'discordant' cases in older infants. It seems possible therefore that, as often suggested, plagiocephaly in older patients with sternomastoid tumours is sometimes acquired, probably because of the tendency of these infants to lie on the side of the occiput opposite to the side of the tumour if the sternomastoid containing the tumour is shorter than the other. In 4 of the older patients in this series the skull asymmetry had been noted by others at birth, and had remained in the same sense, so it seems likely that there are more 'concordant' than 'discordant' cases even in early snfancy.

Sternomastoid tumours in newborn infants have been reported by a number of authors, and there is considerable histological evidence of fibrosis in both sternomastoid muscles before birth (Jones, 1968, with earlier references). There is also some evidence that the sternomastoid muscle bearing the tumour is short before birth, the head being held asymmetrically, and presumably this could occur in one or both or two ways.

(1) The head may be rotated to the opposite side; in this case flattening of the ipsilateral temple and of the opposite occiput might occur, together with a contralateral bat ear.

(2) The head may be flexed towards the affected side. In this case the ear and shoulder on the affected side would be approximated. This as the author quoted below points out, would fit in with the following observations: (a) The ear on the affected side may be short vertically (Voelcker, 1902) observed in $10 \%$ of the present series. (b) The ipsilateral ear lobe may have a transverse crease as if it had been tilted outwards against the shoulderseen in $7 \%$ of the present series.

Additional evidence supporting this theory is provided by consideration of the lower jaw.

Tilting of mandible. In many normal newborn infants the mandible is asymmetrical, one side being tilted upwards when viewed from in front. It has been suggested that this is due to the intrauterine position of the fetus, one ramus of the mandible being pressed against the sternum, if the head is flexed forward and rotated to the opposite side (Chapple, 1959, with illustrations), or against a shoulder if the head is lateroflexed, and either rotated to the same side or not rotated at all (Parmelee, 1931). Abels (1938) claimed that in some infants with sternomastoid tumours the mandible was tilted upwards on the same side as the tumour, but gave no figures.

Table VIII shows the frequency of tilt of the mandible in normal infants, and that it is approximately equally common on the two sides. Common observation shows that the tilt gradually disappears, usually a few months after birth, though occasionally it may still be discerned several years later. Table VII (column (b)) shows the same tendency in children with sternomastoid tumours.

TABLE VIII

Normal Infants

\begin{tabular}{lllll|l}
\hline \multicolumn{3}{c|}{ Position of Mandible } & & No. \\
\hline Left side up-tilted & $\ldots$ & $\ldots$ & $\ldots$ & $\ldots$ & 20 \\
Right side up-tilted & & $\ldots$ & $\ldots$ & $\ldots$ & 17 \\
Symmetrical $\ldots$ & $\cdots$ & $\ldots$ & $\ldots$ & $\ldots$ & 42 \\
\hline
\end{tabular}

Another group of normal infants with marked plagiocephaly was examined, and 36 were noted who also had marked tilting of the mandible. Table IX shows some incomplete correlation between the side of the jaw elevation and temple flattening in this group. Table X, however, shows that in cases with sternomastoid tumours there is a significant $(P<0.001)$ correlation between the side of the tumour and the side of lower jaw elevation, when present; there are too few cases to decide whether there is a significant correlation between 
the side of jaw elevation and the side of temple flattening when both are present, though there is a trend in this direction $(P=0 \cdot 1)$.

TABLE IX

Normal Infants with Plagiocephaly

\begin{tabular}{lllll|c|c|c}
\hline \multicolumn{3}{c|}{ Side of Up-tilt of Mandible } & \multicolumn{2}{c}{ Side of Plagiocephaly } \\
\hline & & & & & Left & Right \\
Left &. & $\ldots$ & $\ldots$ & $\ldots$ & 11 & 8 \\
Right &. & $\ldots$ & $\ldots$ & $\ldots$ & 5 & 12 \\
\hline
\end{tabular}

TABLE $\mathrm{X}$

Sternomastoid Tumour

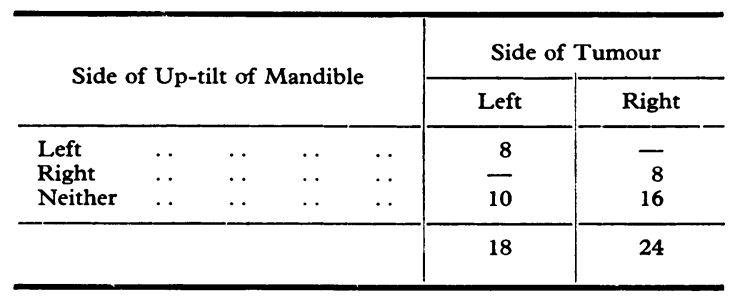

Jaw tilting showed no significant features in children with the other lesions discussed here.

Elevation of the mandible, if present, is therefore on the same side as the tumour, and in this series was present in all the 7 infants seen personally in the first month of life. The incidence becomes small in older children even if torticollis develops (the facial asymmetry seen in later torticoilis is of course quite different). This would fit well with an intrauterine head posture in which the affected sternomastoid muscle is shorter than the other. It might also account for the 'discordant' plagiocephaly noted above in some neonates, for, though the sternomastoid muscle on one side is shorter when the head is rotated away from that side and flexed toward it, if the head is well flexed towards the affected side the sternomastoid may still be short though the head is not rotated, or even if the head is rotated towards the affected side. This might also explain the case noted by Joachimstal (1905) of a girl with a right-sided CDH and a contralateral short sternomastoid (though an actual tumour is not mentioned).

\section{Conclusions}

Evidence in this paper suggests a relation between various unilateral or asymmetrical features. Some of these features are clearly present before birth; in others it seems likely that postural factors operating before birth continue in a similar way post- natally. In the case of sternomastoid tumours it seems likely that the affected muscle is shorter than the other before birth, and the unusual posture of the head has been blamed for the high incidence of breech deliveries $50 \%$ in this series as in a number of others) and of difficult deliveries. Perhaps birth damage gives rise to a tumour in a previously abnormal muscle. This theory is usually ascribed to Chandler and Altenberg (1944), but as they point out Isigkeit (1931) made the same suggestion. The frequency of breech deliveries in $\mathrm{CDH}$ has also been ascribed to the intrauterine posture of the infant.

So far there has been no satisfactory explanation for the left-sided preponderance in normal plagiocephaly, infantile spinal convexities, and $\mathrm{CDH}$, and though it is tempting to inculpate some simple postural mechanism, perhaps partly postnatal, it is difficult to see what this could be. Nurses in hospital do not appear to lay infants on one side more often than the other, nor did those mothers of children in the present series who could recall the management of their infants. Though infants with plagiocephaly often prefer to lie on one particular side, the incidence of left to right-sided $\mathrm{CDH}$ was the same in those with and without plagiocephaly. Finally any theory must explain the fact that a left-sided excess is not universal (e.g. in Vienna-Lorenz and Reiner, 1905; Japan-Miyazaki, 1961; and Israel-Medalie et al., 1966).

In the present series the number of children with congenital heart disease can be ascribed to another interest of the author's, but, as others have noticed, the number who have more than one of the main lesions discussed here seems greater than one would expect, even allowing for the tendency of patients with multiple lesions to arrive at hospitals. More extensive examination of relevant muscles, on the lines described by Jones (1968) in the sternomastoid, might perhaps be informative.

I am indebted to Mr. J. C. F. Cregan and Mr. C. H. Cullen, and to the surgeons of the Royal Manchester Children's Hospital, especially the late Mr. D. D. Cranna, for allowing me to see their patients.

\section{REFERENCES}

Abels, H. (1938). Ueber die Entstehungsweise des sogenannten angeborenen Schiefhalses, seine konstitutions- und erbpathologischen Beziehungen. I. Die unmittelbaren Entstehungsbedingungen (formale Genese). Annales Paediatrici, 152, 4.

Carter, C., and Wilkinson, J. (1964). Persistent joint laxity and congenital dislocation of the hip. Fournal of Bone and foint Surgery, 46B, 40.

Chandler, F. A., and Altenberg, A. (1944). 'Congenital' muscular torticollis. Fournal of the American Medical Association, 125, 476.

Chapple, C. C. (1959). In Textbook of Pediatrics, 7th ed., p. 1250. Ed. by W. E. Nelson. Saunders, Philadelphia.

Danby, P. M. (1962). Plagiocephaly in some 10-year-old children. Archives of Disease in Childhood, 37, 500. 
Ferguson, A. B. (1963). Orthopedic Surgery in Infancy and Childhood, 2nd ed., p. 77. Williams and Wilkins, Baltimore.

Isigkeit, E. (1931). Untersuchungen uber die Heredităt orthopädischer Leiden. III. Der angeborene Schiefhals. Archiv für orthopädische und Unfall-Chirurgie, 30, 459.

Joachimstal, G. (1905). In Handbuch der orthopadischen Chirurgie, Vol. 1, p. 427. G. Fischer, Jena.

Jones, P. G. (1968). Torticollis in Infancy and Childhood. C. C. Thomas, Springfield, Illinois.

Lorenz, A., and Reiner, M. (1905). Die angeborene Hüftverrenkung Frequenz. In Handbuch der orthopädischen Chirurgie. By G. Joachmimstal, Vol. 2, p. 165 . G. Fischer, Jena.

Medalie, J. H., Makin, M., Alkalay, E., Yofe, J., Cochavi, Z., and Ehrlich, D. (1966). Congenital dislocation of the hip: a clinical-epidemiological study, Jeruslaem 1954 to 1960 . Israel Fournal of Medical Sciences, 2, 212.

Miyazaki, K. (1961). Genetic study on the congenital dislocation of the hip (Japanese). Fukushima Medical fournal, 11, 105.

Parmelee, A. H. (1931). Molding due to intra-uterine posture. American fournal of Diseases of Children, 42, 1155.

Voelcker, F. (1902). Bruns' Beitrage zurKlinischen Chirurgie, 33, 1. Wynne-Davies, R. (1968). Familial (idiopathic) scoliosis. A family survey. Fournal of Bone and foint Surgery, 50B, 24.

Correspondence to Dr. G. H. Watson, Royal Manchester Children's Hospital, Pendlebury, near Manchester M27 1HA.

\section{Referees 1970}

A large amount of work is done for the Archives by those who undertake the onerous and rather thankless task of refereeing the papers submitted. The Editors take this opportunity of recording their sincere appreciation to the following who have acted as referees over the past year.

C. M. Anderson

G. C. Arneil

T. M. Barratt

J. Bavin

P. Benson

A. Breckenridge

E. M. Brett

C. O. Carter

A. R. Chrispin

A. E. Claireaux

B. E. Clayton

B. D. Corner

P. Daniel

P. A. Davies

J. A. Davis
G. S. Dawes

A. D. Dayan

C. E. Dent

C. J. Dewhurst

J. L. Emery

N. E. France

G. Gandy

P. S. Gardner

A. V. Hoffbrand

K. Hallidie Smith

R. M. Hardisty

M. Hartog

J. R. Hobbs

A. Holzel

D. Hull
D. Innes Williams

R. S. Jones

G. F. Joplin

E. G. Knox

G. M. Komrower

G. H. Lathe

D. Lawson

B. Levin

S. M. Lewis

J. K. Lloyd

V. Logue

R. A. McCance

R. D. G. Milner

D. Morley
G. K. Naylor

M. Purves

P. P. Rickham

K. B. Rogers

J. F. Soothill

L. B. Strang

S. J. Strich

J. M. Tanner

E. W. B. Varley

R. H. R. White

B. Wharton

E. M. Widdowson

J. S. Wigglesworth

O. H. Wolff 